\title{
Pembinaan masyarakat desa untuk peningkatan pendapatan melalui teknologi budidaya kepiting soka di Desa Pulau Cawan Kecamatan Mandah Kabupaten Indragiri Hilir
}

\author{
T Ersti Yulika Sari*, Usman, Niken Ayu Pramungkas, Mulyadi Idris, Sumarto, Eni Yulinda, dan \\ Ridar Henrik
}

Fakultas Perikanan dan Kelautan, Universitas Riau

* nonnysaleh2010@ hotmail.com

\begin{abstract}
Abstrak. Kepiting soka adalah kepiting bakau yang dibudidayakan dan dilakukan pemanen disaat molting sehingga cangkangnya menjadi lunak dan mudah untuk dikonsumsi. Tujuan dari pengabdian ini adalah untuk meningkatkan pendapatan masyarakat Desa Pulau Cawan, Kecamatan Mandah, Kabupaten Indragiri Hilir melalui budidaya kepiting soka dengan memperkenalkan teknik budidaya yang ramah lingkungan, namun dapat menghasilkan nilai tambah dari segi peningkatan ekonomi keluarga melalui budidaya kepiting soka. Pelatihan teknik-teknik budidaya kepiting soka dan pelatihan pembangunan konstruksi wahana budidaya (crabs box). Kegiatan pengabdian ini dilaksanakan dengan menggunakan beberapa metoda pendekatan yaitu memberikan pemahaman kepada masyarakat yang dilaksanakan dalam bentuk FGD (Focus Group Discussion). Serta melakukan diskusi dan praktek budidaya kepiting untuk menggali informasi tentang pemahaman budidaya yang ramah lingkungan, menjaga ekosistem mangrove, peningkatan pendapatan rumah tangga melalui penambahan nilai terhadap hasil tangkapan dan solusi mengenai adanya nelayan dari luar desa yang melakukan cara-cara penangkapan yang merusak, yaitu dengan memberi racun. Serangkaian kegiatan penyuluhan yang dilakukan mengenai teknik budidaya kepiting cangkang lunak (soka) dapat diterima dengan baik oleh nelayan penangkap kepiting yang ada di Desa Pulau Cawan. Peningkatan pengetahuan dan keterampilan nelayan penangkap kepiting dalam budidaya kepiting cangkang lunak yang di letakkan dalam kotak kepiting (crab box) dapat menjadi bekal agar kegiatan budidaya ini dapat terus berlanjut, dan Desa Pulau Cawan dapat menjadi desa percontohan teknik budidaya kepiting cangkang lunak (soka) untuk beberapa tahun ke depan.
\end{abstract}

Kata kunci: pembinaan masyarakat, peningkatan pendapatan, budidaya, kepiting soka, desa pulau cawan.

\begin{abstract}
Soft-shelled crabs are mangrove crabs that are cultivated and harvested while moulting so that their shells are soft and easy to consume. The purpose of this activity is to increase the income of the people of Pulau Cawan Village, Mandah District, Indragiri Hilir Regency through the cultivation of soft-shelled crabs. by introducing environmentally friendly cultivation techniques, but can produce added value in terms of improving the family's economy through softshelled crab cultivation. Training on softwater crab cultivation techniques and training in the construction of aquaculture ponds (crabs box). These community service activities are carried out using several approach methods, namely providing understanding to the community carried out in the form of FGD (Focus Group Discussion), as well as conducting discussions and practice on crab cultivation to dig up information about understanding environmentally friendly cultivation, protect mangrove ecosystems, increase household income through adding value to catches and solutions regarding fishermen from outside the village who use destructive fishing, by giving poison. A series of services activities conducted on soft shell crab farming techniques (shelled) can be received well by the crab catch fisherman in Desa Pulau Cawan. Increased knowledge and skills of crab catch fishermen in the cultivation of soft shell crabs placed in crab boxes can provide provisions so that these farming activities can continue, and Desa Cawan Island can become a pilot village for soft shell crab cultivation techniques for the next few years.
\end{abstract}

Keywords: community development, increased income, cultivation, soft-shelled crabs, desa pulau cawan 
To cite this article: Sari, T. E. Y., Usman, N. A. Pramungkas, M. Idris, Sumarto, E. Yulinda, \& R. Henrik. 2019.

Pembinaan masyarakat desa untuk peningkatan pendapatan melalui teknologi budidaya kepiting soka di Desa Pulau Cawan Kecamatan Mandah Kabupaten Indragiri Hilir. Unri Conference Series: Community Engagement 1: 228-

234. https://doi.org/10.31258/unricsce.1.228-234

(C) 2019 Authors

Peer-review under responsibility of the organizing committee of Seminar Nasional Pemberdayaan Masyarakat 2019

\section{PENDAHULUAN}

Salah satu potensi hutan mangrove yang dapat dimanfaatkan oleh masyarakat adalah kepiting bakau (Scylla serrata). Kepiting bakau merupakan salah satu organisme perairan bernilai ekonomis tinggi, penghuni daerah estuaria dan mangrove dan telah dibudidayakan secara komersial di beberapa negara tropis (Saidah dan Sofia, 2016). Jenis kepiting ini diminati masyarakat baik, di pasaran dalam negeri maupun luar negeri karena rasa dagingnya yang lezat dan bernilai gizi tinggi.

Meningkatnya permintaan konsumen terutama dalam memenuhi kebutuhan dalam negeri khususnya dalam melayani permintaan hotel dan restoran maupun sebagai komoditas ekspor menjadi dasar pengembangan budidaya kepiting soka di Kabupaten Indragiri Hilir. Budidaya kepiting soka diharapkan dapat memberikan peningkatan pendapatan nelayan. Upaya untuk menghasilkan kepiting soka dapat dilakukan dengan merangsang kepiting tersebut untuk molting (ganti kulit). Penggunaan ekstrak bayam (vitomolt) dapat mempercepat proses molting dan berwawasan lingkungan. Molting pada kepiting dipengaruhi faktor internal berupa umur dan jenis kelamin, serta faktor eksternal berupa pakan dan kondisi lingkungan (Fujaya et al, 2013)

Dalam rangka mematangkan konsep kawasan perikanan sebagai basis industrialisasi kelautan dan perikanan di Provinsi Riau umumnya dan kabupaten Indragiri Hilir khususnya sekaligus melakukan pemberdayaan masyarakat melalui program diversifikasi usaha untuk meningkatkan pendapatan, perlu disusun upaya-upaya teknis melalui pengembangan pengetahuan dan keterampilan masyarakat pesisir melalui kegiatan budidaya kepiting soka di Desa Pulau Cawan Kecamatan Mandah Kabupaten Indragiri Hilir.

Desa Pulau Cawan, sebagai salah satu desa yang memiliki sumberdaya kepiting yang cukup potensial, tetapi hingga saat ini belum ada dilakukan upaya untuk melakukan budidaya kepiting bakau. Masyarakat melakukan penangkapan terhadap kepiting yang tersedia di alam. Untuk mencegah berkurangnya populasi kepiting bakau akibat penangkapan yang berlebih, sehingga perlu dilakukan pengenalan terhadap teknologi budidaya kepiting bakau khususnya kepiting soka. Selain untuk menjaga kelestarian dari kepiting bakau, juga nantinya diharapkan dapat meningkatkan pendapatan pembudidaya melalui diversifikasi produk.

Ada beberapa kendala yang dihadapi petambak sehubungan dengan kegiatan budidaya hewan ini, antara lain: waktu yang dibutuhkan untuk produksi kepiting lunak relatif lama (berkisar antara 1 minggu hingga 4 bulan tergantung ukuran kepiting) karena kepiting harus ditunggu hingga molting. Konsekuensi dari keadaan ini adalah biaya produksi meningkat. Untuk mengatasi masalah ini maka selama 15 tahun terakhir, petani melakukan teknik mutilasi untuk memproduksi kepiting lunak. Teknik mutilasi adalah mematahkan paling sedikit 8 kaki kepiting untuk merangsang molting. Tujuan dari pengabdian ini adalah untuk meningkatkan pendapatan masyarakat Desa Pulau Cawan, Kecamatan Mandah, Kabupaten Indragiri Hilir melalui budidaya kepiting soka dengan memperkenalkan teknik budidaya yang ramah lingkungan, namun dapat menghasilkan nilai tambah dari segi peningkatan ekonomi keluarga melalui budidaya kepiting soka. Pelatihan teknik-teknik budidaya kepiting soka dan pelatihan pembangunan konstruksi wahana budidaya (crabs box). Manfaat dari pengabdian ini untuk meningkatkan keterampilan anggota kelompok usaha bersama pembudidaya kepiting untuk memberikan penguatan peran anggota dalam kelompok untuk mendukung pengembangan perekonomian. Meningkatkan produksi dan kualitas kepiting soka yang 
dikelola kelompok pembudidaya untuk mendukung pengembangan pengetahuan rakyat dan peningkatan pendapatan.

Masyarakat sasaran adalah pembudidaya atau nelayan penangkap kepiting bakau yang ada di Desa Pulau Cawan, Kecamatan Mandah. Desa Pulau Cawan telah sejak lama terkenal sebagai daerah penghasil kepiting dan udang yang di distribusikan ke ibukota kabupaten bahkan hingga keluar kabupaten.

\section{Perumusan Masalah}

Desa Pulau Cawan, Kecamatan Mandah, Kabupaten Indragiri Hilir sebagai salah satu desa yang memiliki sumberdaya kepiting yang cukup potensial, tetapi hingga saat ini belum ada dilakukan upaya untuk melakukan budidaya kepiting bakau. Masyarakat melakukan penangkapan terhadap kepiting yang tersedia di alam. Hal ini tentu saja akan mengakibatkan terjadinya penangkapan yang berlebihan apabila permintaan terhadapa kepiting bakau terutamanya bercangkang lunak (soka) meningkat. Untuk mencegah berkurangnya populasi kepiting bakau akibat penangkapan yang berlebih, sehingga perlu dilakukan pengenalan terhadap teknologi budidaya kepiting bakau khususnya kepiting soka. Selain untuk menjaga kelestarian dari kepiting bakau, juga nantinya diharapkan dapat meningkatkan pendapatan pembudidaya melalui diversifikasi produk. Ada beberapa kendala yang dihadapi petambak sehubungan dengan kegiatan budidaya hewan ini, antara lain: waktu yang dibutuhkan untuk produksi kepiting lunak relatif lama (berkisar antara 1 minggu hingga 4 bulan tergantung ukuran kepiting) karena kepiting harus ditunggu hingga molting. Konsekuensi dari keadaan ini adalah biaya produksi meningkat.

\section{METODE PENERAPAN}

\section{Waktu dan Tempat}

Kegiatan budidaya kepiting cangkang lunak ini dilaksanakan di Desa Pulau Cawan Kecamatan Mandah Kabupaten Indragiri Hilir. Koordinasi dengan Kepala Dinas Kelautan dan Perikanan Kabupaten Indragiri Hilir dilaksanakan pada bulan Maret 2018. Survey lokasi kegiatan dilaksanakan pada Bulan Mei 2018, dengan melakukan observasi terhadap calon lokasi kegiatan dan kesiapan masyarakat untuk menerima informasi. Pelaksanaan pengabdian pada bulan September 2018 di Balai Desa Pulau Cawan, dihadiri oleh 30 nelayan penangkap kepiting.

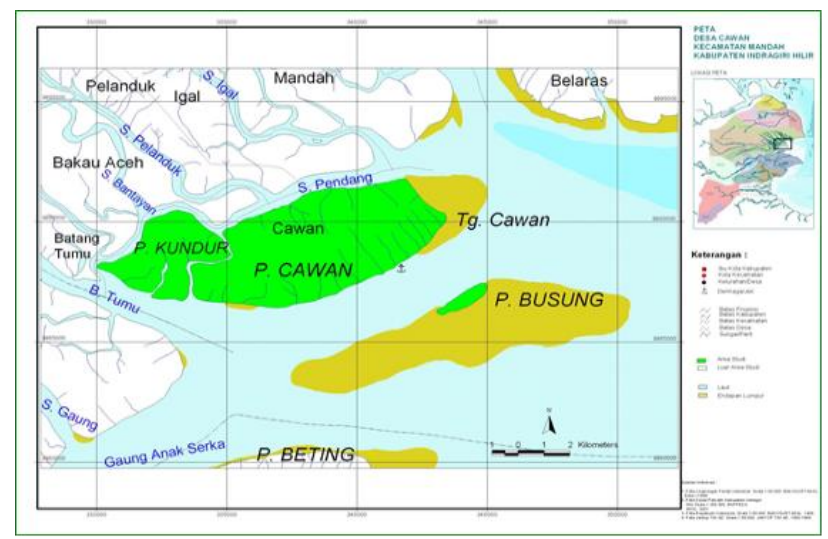

Sumber: Monografi Desa Pulau Cawan, 2008

Gambar 1. Peta Desa Pulau Cawan, Kecamatan Mandah, Indragiri Hilir, Riau

\section{Strategi Pelaksanaan}

Kegiatan pengabdian ini dilaksanakan dengan menggunakan beberapa metoda pendekatan yaitu memberikan pemahaman kepada masyarakat yang dilaksanakan dalam bentuk FGD (Focus Group Discussion). Tahap awal dilaksanakan tanggal 22-23 September 2018 bertempatan di balai Desa Pulau Cawan, dengan memberi ceramah mengenai konsep pemanfaatan sumberdaya ikan secara bertanggung jawab sesuai dengan kaidah Code of Conduct for Responsible Fisheries Kepada Masyarakat Desa Pulau Cawan. Serta melakukan diskusi dan praktek budidaya kepiting untuk menggali informasi tentang pemahaman budidaya yang ramah lingkungan, menjaga ekosistem mangrove, peningkatan pendapatan rumah tangga melalui penambahan nilai 
terhadap hasil tangkapan dan solusi mengenai adanya nelayan dari luar desa yang melakukan cara-cara penangkapan yang merusak, yaitu dengan memberi racun.

\section{Mekanisme Pelaksanaan}

Tim melakukan persiapan-persiapan awal seperti koordinasi dengan Pemerintah Kabupaten Indragiri Hilir dalam hal ini Dinas Kelautan dan Perikanan dan pihak Universitas Riau mengenai teknis pelaksanaan kegiatan. Hasil koordinasi ini diharapkan juga menjadi sosialisasi adanya kegiatan dan sepenuhnya dapat mendukung kegiatan ketika berlangsung. Selain itu akan dilakukan persiapan materi, pembagian tugas, persiapan alat, dan pemagangan 2 orang calon pengelola pada tambak kepiting soka milik UNRI.

\section{HASIL DAN PEMBAHASAN}

\section{Sosialisasi Kegiatan}

Tim terlebih dahulu melakukan pendekatan dengan cara FGD, sebelum melaksanakan penyuluhan dan praktek budidaya kepiting soka. Hal ini dilakukan untuk memberikan informasi awal mengenai teknologi budidaya dengan menggunakan ekstrak bayam. Tim juga mengajak nelayan untuk menentukan daerah tangkapan kepiting dengan melingkari peta yang telah disediakan. Bersama nelayan kepiting, tim mengajak untuk membuat peta musim penangkapan ikan di Desa Pulau Cawan (Gambar 2).
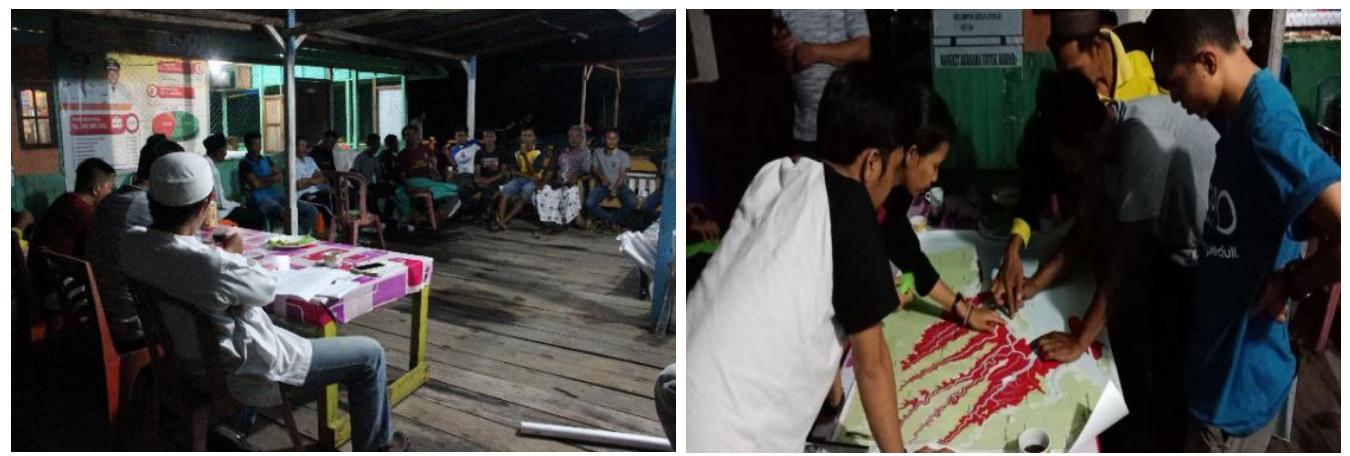

Gambar 2. FGD dengan masyarakat nelayan

Selanjutnya, dilakukan survey lokasi budidaya. Kesehatan tanah perlu diperhatikan terutama adanya zatzat toksik yang menumpuk di dasar tambak seperti H2S akibat kotoran hewan budidaya itu sendiri dan kelebihan pakan. Keadaan ini ditandai dengan tanah yang berwarna hitam dan berbau busuk. Bila kondisi tambak seperti itu maka dianjurkan untuk melakukan rehabilitasi dengan pengeringan dan pengangkatan Lumpur hitam tersebut karena meskipun kepiting yang dipelihara untuk produksi kepiting lunak tidak hidup di dasar tambak namun, kondisi tanah yang demikian akan memengaruhi kualitas air (Gambar 3).
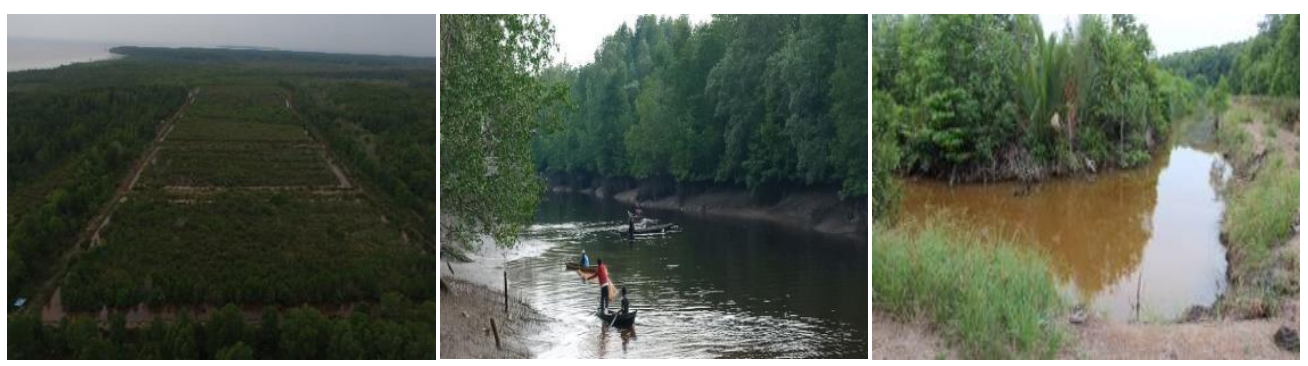

Gambar 3. Beberapa Lokasi Tambak Kepiting Soka

Penyampaian materi disampaikan sesuai dengan metode ceramah, diskusi dan praktek, kegiatan di ruangan balai desa Pulau Cawan (Gambar 4). 

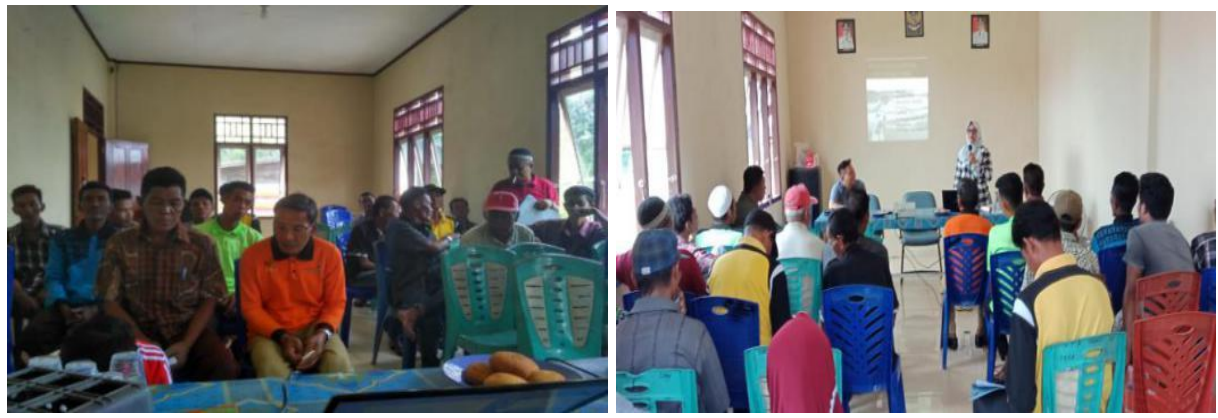

Gambar 4. Penyampaian Materi

\section{Penyediaan bahan baku dan penanganannya}

Bahan baku utama yang dibutuhkan dalam kegiatan ini adalah bibit kepiting dan pakan. Selain itu bahan baku pendukung adalah ekstrak bayam (vitomolt). Bahan baku kepiting diperoleh dari suplier kepiting setempat. Bahan baku pakan diperoleh dari nelayan setempat berupa ikan rucah kering. Vitomolt diperoleh dari Laboratorium Bioteknologi Pusat Kegiatan Penelitian UNHAS.

\section{Pendampingan Teknologi}

Proses produksi kepiting lunak meliputi: penyiapan lahan, pemilihan bibit, penyuntikan vitomolt, penebaran, pemberian pakan, pengelolaan kualitas air, pengawasan, panen, dan pasca panen.

\section{Penyiapan lahan}

Persiapan yang dilakukan meliputi pengeringan dasar tambak dan pemberantasan hama menggunakan saponin.

\section{Pemilihan bibit}

Bibit yang akan digunakan untuk produksi kepiting lunak harus diperhatikan hal-hal berikut: warna cerah/normal tidak pucat, tidak cacat, tidak ada kerak menempel yang ditandai dengan warna yang tidak lazim, tidak sedang bertelur, dan tidak akan segera molting. Ukuran kepiting antara 70-120 g per ekor.

\section{Penyuntikan ekstrak bayam (vitomolt)}

Sebelum penebaran, kepiting diaklimatisasi dengan air tempat mereka akan ditebar dengan cara mencelupkan kepiting ke dalam air tambak beberapa saat. Setelah kepiting nampak segar kembali, bibit disuntik dengan larutan vitomolt sebanyak $1 / 10 \mathrm{~mL}$ pada pangkal kaki renang. Vitomolt tersedia dalam bentuk serbuk sehingga harus dilarutkan terlebih dahulu dengan air steril sebelum digunakan untuk penyuntikan. Metode penyiapan larutan vitomolt dapat dilihat pada kotak kemasan. Pelatihan penyuntikan diberikan kepada kelompok tani mitra dan staf teknis DKP (Gambar 5).

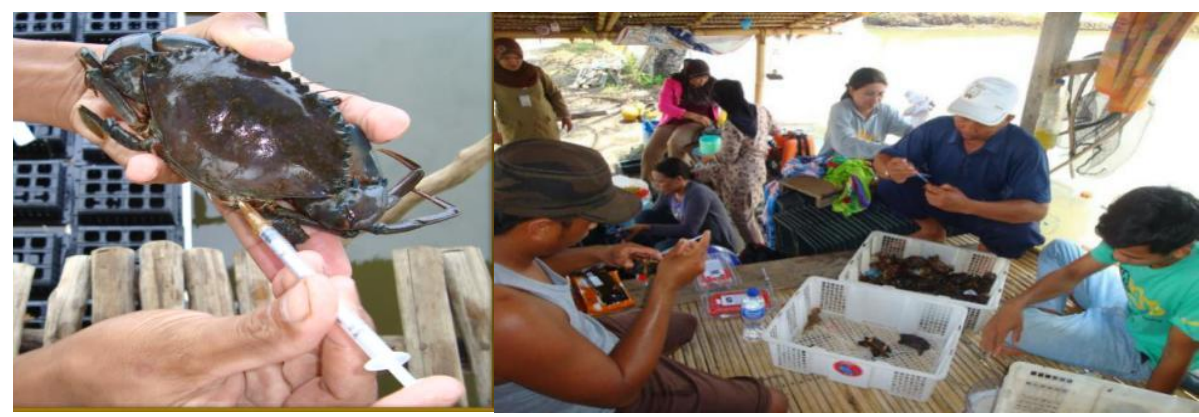

Gambar 5. Penyuntikan Vitamolt pada ujung kaki renang kepiting

\section{Penebaran}

Setelah penyuntikan kepiting di tebar ke dalam crab box secara individu. Crab box di tempatkan di atas rakit yang diletakkan di permukaan tambak. 


\section{Pemberian pakan}

Pemberian pakan dilakukan sekali dalam dua hari, yaitu setiap sore hari menjelang malam sebanyak 3 $5 \%$ berat badan berupa ikan rucah kering tawar.

\section{Pengelolaan kualitas air}

Kualitas air merupakan salah satu faktor lingkungan yang sangat berpengaruh terhadap fisiologi organisme perairan. Pertumbuhan kepiting dipengaruhi oleh suhu, salinitas, $\mathrm{pH}$, dan amoniak. Suhu optimum untuk kepiting adalah 25-35oC. Salinitas antara 15-30 ppt tergantung spesies, Scylla serrata lebih cocok dipelihara pada perairan dengan salinitas tinggi, sedangkan S.olivacea dan S. transquabarica pada salinitas yang rendah. $\mathrm{pH}$ air berkisar antara 7,2-7,8. Amoniak toksik dan nitrit sebaiknya hanya berada pada kisaran 0.5-1.0 ppm. Agar kualitas air tetap optimal maka pergantian air dilakukan mengikuti siklus pasang surut.

\section{Pengawasan dan Panen}

Dalam budidaya kepiting lunak, pengawasan sangat menentukan kualitas kepiting lunak yang dihasilkan. Dalam budidaya kepiting lunak pengawasan dilakukan secara rutin, siang malam, setiap 2-3 jam. Persentase molting tertinggi biasanya pada jam 06 pagi dan jam 10 malam. Indikator kepiting telah molting adalah bila di dalam crabbox nampak ada 2 kepiting maka itu adalah indikator bahwa kepiting telah berganti kulit. Sesungguhnya hanya ada 1 kepiting dengan kulit yang baru, yang lainnya adalah kulit kepiting keras yang ditanggalkan.

\section{Pascapanen}

Panen dilakukan dengan mengangkat kepiting molting dari air tambak dan diletakkan dalam keranjang khusus secara hati-hati. Setelah panen, kepiting lunak direndam dalam air tawar kurang lebih 1jam untuk membersihkannya dari berbagai kontaminan sekaligus mereduksi garam yang terdapat dalam tubuh (Gambar 6).

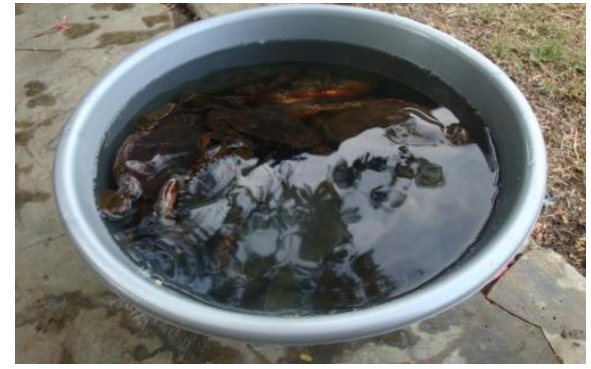

Gambar 6. Perendaman kepiting lunak dalam air tawar

Tim pengabdian juga memperagakan pengolahan pasca panen, yaitu membuat kepiting soka krispi. Dan pada pertemuan tersebut, dapat dimakan bersama setelah di goreng (Gambar 7)
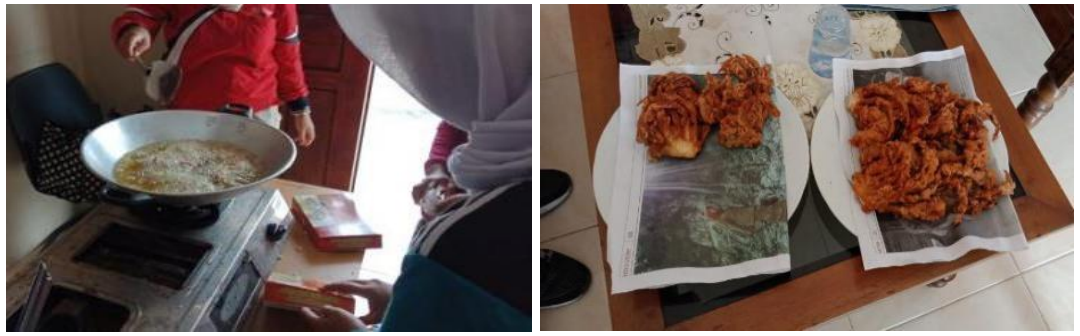

Gambar 7. Pengolahan Kepiting Soka 
Tabel 1. Hasil evaluasi sikap antusiasme peserta selama mengikuti penyuluhan

\begin{tabular}{cccc}
\hline Antusiasme peserta & Skor & Jumlah & Total skor \\
\hline Sangat rendah & 1 & 0 & 0 \\
Rendah & 2 & 0 & 0 \\
Sedang & 3 & 1 & 3 \\
Tinggi & 4 & 14 & 64 \\
Sangat tinggi & 5 & 4 & 20 \\
\hline Total & & & 87 \\
Rerata & & 4,35 \\
\hline
\end{tabular}

Hasil pengamatan terhadap sikap antusiasme peserta penyuluhan menunjukkan bahwa hampir semua peserta menunjukkan antusiasme tinggi atau sangat tinggi. Hanya 1 orang yang menunjukkan antusiasme sedang (Tabel 1). Rerata skor antusiasme peserta adalah 4,35 atau berkisar antara antusias tinggi dan sangat tinggi. Hal ini menunjukkan bahwa kebanyakan dari masyarakat tersebut ingin mendapatkan bekal pengetahuan tentang budidaya kepiting cangkang lunak dalam crab box serta langkah-langkah pengelolaan yang perlu dilakukan agar dapat melakukan usaha tersebut dengan baik.

\section{KESIMPULAN}

Serangkaian kegiatan penyuluhan yang dilakukan mengenai teknik budidaya kepiting cangkang lunak (soka) dapat diterima dengan baik oleh nelayan penangkap kepiting yang ada di Desa Pulau Cawan. Dari evaluasi yang dilakukan sebelum dan setelah dilakukannya kegiatan penyuluhan ada peningkatan pengetahuan dan keterampilan oleh nelayan penangkap kepiting di Desa Pulau Cawan

Peningkatan pengetahuan dan keterampilan nelayan penangkap kepiting dalam budidaya kepiting cangkang lunak yang di letakkan dalam kotak kepiting (crab box) dapat menjadi bekal agar kegiatan budidaya ini dapat terus berlanjut, dan Desa Pulau Cawan dapat menjadi desa percontohan teknik budidaya kepiting cangkang lunak (soka) untuk beberapa tahun ke depan.

\section{DAFTAR PUSTAKA}

Fujaya Y, Trijuno DD, dan Husnidar. 2013. Pengaruh Siklus Bulan Terhadap Dinamika Hormon Ecdysteroid Kaitannya dengan Aktivitas Molting Kepiting Bakau (Scylla olivacea) pada Budidaya Kepiting Cangkang Lunak [skripsi]. Makassar (ID): Universitas Hasanuddin.

Saidah, S. dan L. A. Sofia. 2016. Pengembangan Usaha Pembesaran Kepiting Bakau (Scylla spp) Melalui Sistem Silvofishery. Jurnal Hutan Tropis 4(3): 265-272. 